\title{
An Survey and Adoption Framework for Customised Advertisement in Mobile Cloud Structures
}

\author{
P. Naresh ${ }^{1}$, Dasari Rajesh ${ }^{2}$ \\ ${ }^{1,2}$ Computer Science and Engineering, Rise Group of Institutions, Ongole, India
}

\begin{abstract}
Since Cloud Computing is big Buzz word been around now, Customization or Personalized Targeting has raised the bar higher. Technological improvements has enabled in mining customer behaviour towards their buying capacity. Personalized advertisement is an efficient way of matching Customer buying preferences with potential products from various vendors. We propose an application architecture that uses smart Mobiles and cloud computing to distribute in real time advertisement information to clients by matching their location, preferences and price range with available products. Our tests of the proposed application show its applicability in customized advertisement.
\end{abstract}

Keywords: customized advertisement, cloud application, mobile Android applications

\section{Introduction}

Traditional marketing is passive, that means people get the ad not while they are active, on the go, but at home while resting. Shopping is emotional, having the ad at the right time and the right place, having it rich with multimedia videos that come in your computer through the Cloud will be more beneficial. In this paper we build a new application for android users that get special ads through the cloud. It can be activated by voice by a busy travelling manager. When we talk about the traditional marketing we mean the usual flyers, e-mails or TV-ads. Busy people read or most of the times throw those way. As for e-mails they don't even open them when $\log$ in their accounts and find a dozens of e-mails that need an answer. What about the TV ads? It's known that shopping is emotional with an exponential negative curve [24], which means that if they watch the ads at night, by the next morning that emotion will be close to 0 . By using Cloud computing you can send ads to customer's cell phones, at the right time and for the right customer. The ads can be loaded with multimedia effects as we know about the unlimited storage power as a great feature of cloud.

\section{Cloud Computing}

Cloud computing is the new paradigm of computing empowered by Internet. This is a new application that is bringing thousands of new applications, giving us the possibility to go faster and with greater quality in everything. In other words Cloud Computing means the renting of infrastructure and software, as well as bandwidths, under defined service conditions [25]. These components can be adjusted daily to the needs of the customer and offered with a great availability and security.

The name "cloud computing" comes from the symbol used to represent a group of networked computers that are connected to the Internet. The network engineers often use this symbol (a puffy cloud shape) to draw diagrams of computer networks. This symbol condenses away the unnecessary details about what is in that cloud of linked computers. For instance, when you think about the Internet, the precise location of the computers it relies on usually doesn't matter to you. Since so many computers are involved, they are spread all over the world. Similarly, the precise configuration of these computers also doesn't matter in many cases. They might be powerful or weak, servers or desktops. But because they are so numerous, their aggregate power is immense. These ideas - Internet scale and abstraction of unnecessary detail - are at the core of cloud computing. You are probably already using cloud-computing applications, such as Gmail. Other cloud-based applications include Facebook and Flickr [8].

\section{Cloud and Marketing}

Cloud Computing deals with the big data and this reshapes the marketing role.[3] Marketing is being redefined in this era, creating many cloud-delivered, self-service applications and services in one side and web-connected consumers on the other. As a result the effective marketing is both broader and more focused than it has been in the past. "Broader" here means that the channels are no longer limited to radio, TV, print and online publications but social networks as well. Data flowing in via Twitter and Facebook is an important source of market intelligence [13-22].

\section{Customized Advertising}

Customized advertising is a type of advertising whereby advertisements are placed so as to reach consumers based on various traits such as demographics, psychographics, behavioural variables (such as product purchase history), and firmographic variables or other second-order activities which serve as a proxy for these consumer traits [9]. The purpose is justified by the fact that the ads are time sensitive [24].

These are difficult times for advertisers. Gone are the days of three network television channels; dead or dying are many of the powerhouse magazines of yesteryear; television viewers with DVRs or Tivo can record programs and view them later (or just later on in the live broadcast), zooming right past 


\section{International Journal of Science and Research (IJSR) \\ ISSN (Online): 2319-7064}

Index Copernicus Value (2013): 6.14 | Impact Factor (2014): 5.611

advertisements. Advertisers, today more than ever, want to reach the most consumers for the fewest dollars, all the while reaching the "right" people. So, rather than running a commercial for a woman's shampoo during a show that might have lots of viewers, but of the wrong target demographic, companies can strategically pick the shows and networks whose ratings data tells them that a certain audience (women, for this example) is most likely to be watching. This strategy is known as customized advertising - it's an attempt to reach a specific demographic, be it people of a certain age, gender, social class, profession or ethnicity. And that's just one example.

With today's technology, customized advertising is becoming more pervasive. For example, Facebook can pull information from your profile and select the ads that appear on your screen. Similarly, your Internet search terms, in the moment and over time, may determine the next ad you see on a search results page or on a specific Web site in the search engine's ad network.

The targeting is getting more accurate all the time. In 2009, Cablevision Systems rolled out a project to serve targeted ads to markets in New York and New Jersey. The technology was able to send television advertisements to certain households and not others based on statistical information about the residents. Income data, ethnicity and gender were some of the items used to do the targeting. The cable company used data provided by credit ratings agency

Experian to match the data to various blocs of customers

For even simpler examples of customized advertising that have nothing to do with computers or TVs, you could always go old school and check your mailbox. If you've not yet managed to rid your life of junk mail, chances are some of your mail was sent to you based on past buying habits, the demographics of your area, and so on.

We target customers from their interest declared in their registered purchases. To create value for the targeted customers the following steps are needed:

\section{Segmentation:}

Divide the total market into smaller segments. customers.

\section{Target selection:}

Aggregate consumers with similar needs or demand patterns that are:

Homogeneous Demand-uniform, everyone demands the product for the same reason(s), usually rare.

Clustered Demand-consumer demand classified in two or more identifiable clusters, that applies for most customers.

\section{Differentiation:}

Differentiate the market offering to create superior customer value.

\section{Positioning:}

Position the market offering in the minds of target customers.

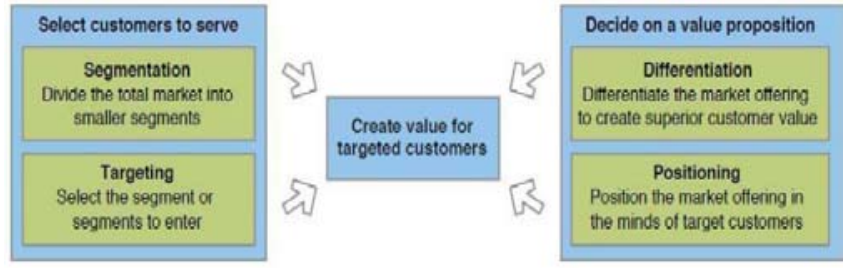

Figure 1: Steps in market segmentation, targeting, and positioning.

Most targeted new media advertising currently uses secondorder proxies for targeting, such as tracking online or mobile web activities of consumers, associating historical webpage consumer demographics with new consumer web page access, using a search word as the basis for implied interest, or contextual advertising.

Addressable advertising systems serve ads directly based on demographic, psychographic, or behavioral attributes associated with the consumer(s) exposed to the ad. These systems are always digital and must be addressable in that the end point which serves the ad (set-top box, website, or digital sign) must be capable of rendering an ad independently of any other end points based on consumer attributes specific to that end point at the time the ad is served. Addressable advertising systems therefore must use consumer traits associated with the end points as the basis for selecting and serving ads.

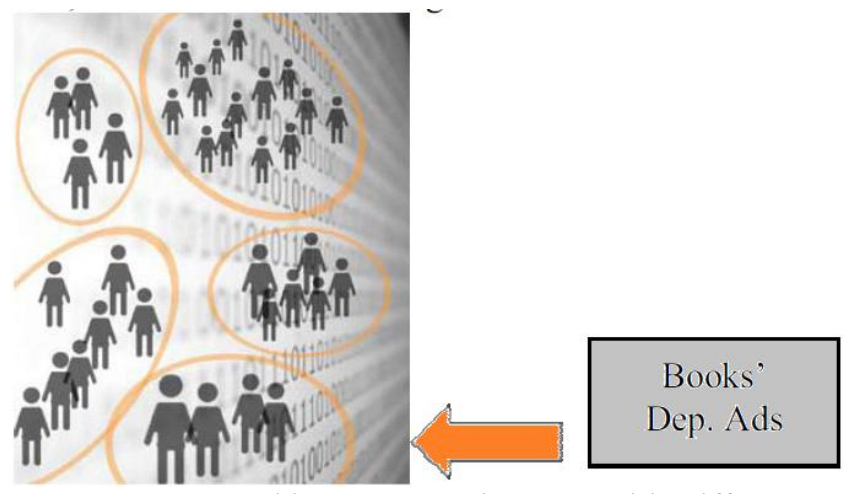

Figure 2: Matching customer interests with Different departments advertisements

\section{Mobile Marketing}

Mobile Marketing is the new marketing era emerged from the great use of smart phones worldwide. Customers are most of the time on the move. No consumers are on their phones all day long. That's why the new way of marketing is the mobile Marketing. Marketers, are supposed to "go where the consumers are and get there first". Nowadays the consumers are looking to their mobile device for shopping, searching, entertainment, socializing and brand interaction. Often, the challenge is resourcing to manage the program; however, from a testing perspective, now is the time to engage.

Mobile is arguably the closest you can get to the consumer. There is no other device that is as personal (everybody has their own phone), as pervasive (is with you all of the time), and provides the opportunity for proximity. As marketers seek to understand - and leverage - a consumer's path to purchase, mobile devices have the potential to be a 


\section{International Journal of Science and Research (IJSR) \\ ISSN (Online): 2319-7064}

Index Copernicus Value (2013): 6.14 | Impact Factor (2014): 5.611

tremendous enabler. The power (in the future) to determine that a target consumer is driving in the proximity of your restaurant and then feed them an immediate message or coupon is unprecedented. As reported in [10], Americans spent 2.7 hours per day socializing on their mobile phones more than twice the time they spent eating. $75 \%$ of the globe now has a mobile phone offering access to developed markets as well as emerging regions [11]. Mobile will truly enable marketers to connect at the right time, in the right place, with the right individual. Finally, mobile to overtake fixed internet access by 2014 [12].

\section{Architecture}

In our scenario, different managers from different departments orders the activation of an ad to the group of customers interested in their departments merchandises. Since in our application we have added the voice activation feature, the busy managers don't even need to type the command for application activation. It's enough just to say it.

The architecture of our solutions, as shown in Fig. 3, contains two major components: First, an Android application that will be able to recognize the voice and will transmit it as a text into a web application. Second, a web application that will choose the new ad from the Ads Database and will send it back into Android application (Customers phone) the ad that the person is interested in. Therefore, performs the connection of a user with a database and the exchange of the data with an Android Application. Android smart phones will be connected to cloud as shown in Fig. 4.

The web application is implemented in the cloud and there is no need for distributing, downloading or installing its software. These conveniences make web applications a very popular choice [6]. In addition, the well known features of the servlets and JSPs such as portability, powerful, efficiency, safety, easy integration, extensibility, inexpensive cost, security, and performance [7] make the choice of a classic web application to provide a connection with a database very appealing. Furthermore, the commodity to host a web application inside a Cloud platform makes the web application very much appropriate to include it as a component in an approach, where this component will provide all the operations with a database. Also, an important aspect is the testing process the technical approach. Hosting the database and the web application in cloud facilitates the testing of the application.

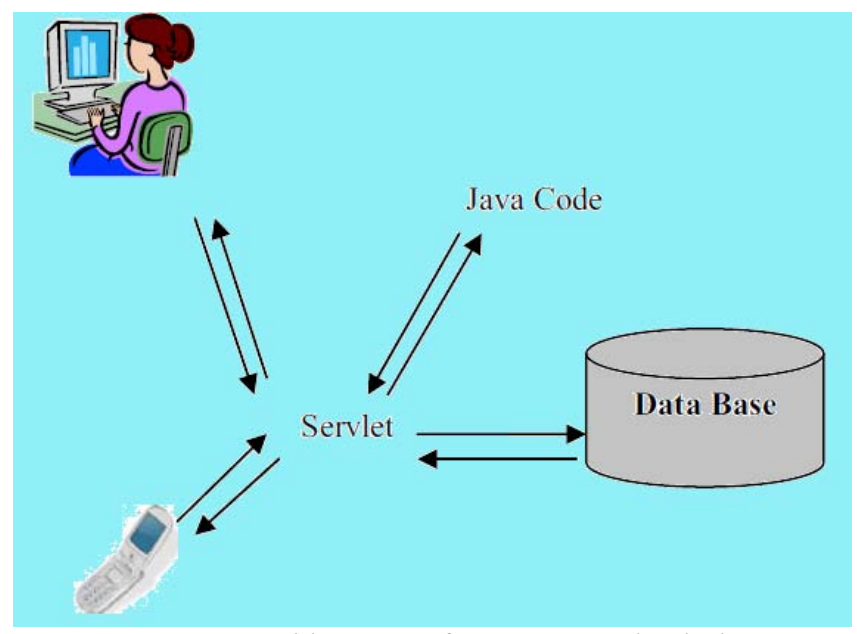

Figure 3: Architecture of our proposed solution.

\section{Android Application}

Android is a Linux-based operating system for mobile devices such as smart phones and tablet computers. It is developed by the Open Handset Alliance, led by Google, and other companies [22]. The language used is Java.

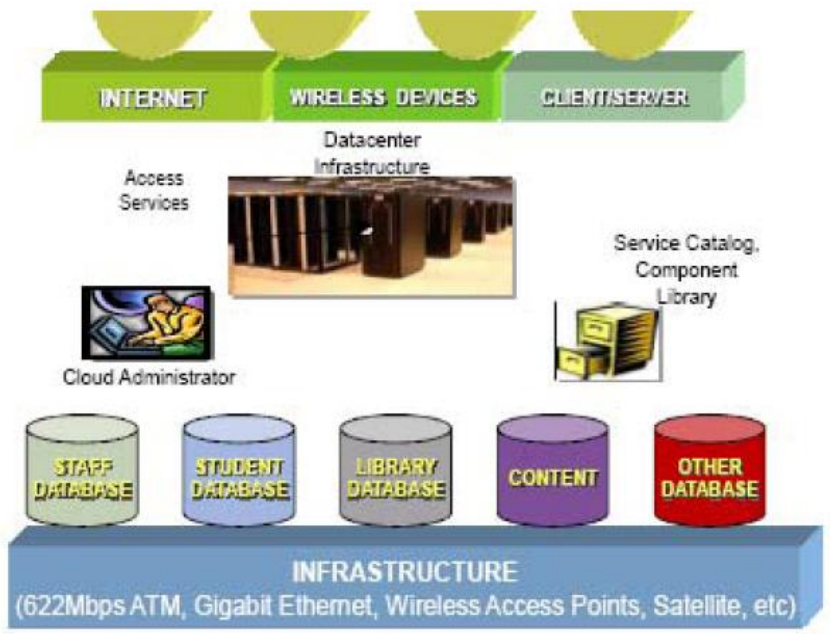

Figure 4: Android (Wireless) users connected through the Cloud.

The interface of the Android application contains a button, microphone image and a text field to display the corresponding text. The Android application is able to convert the voice into a text. The technique used in this case is based in Google speech recognizer intent.

\section{Conclusions}

We proposed and implemented an application architecture that uses Android smart phones and cloud computing to distribute in real time advertisement to clients by matching their location, preferences and price range with available products. Ads are time sensitive. That means that sending the ad in interested customers and in the right time will increase the profits. Our tests of the proposed application show its applicability in customized advertisement. 


\section{International Journal of Science and Research (IJSR) \\ ISSN (Online): 2319-7064}

Index Copernicus Value (2013): 6.14 | Impact Factor (2014): 5.611

\section{References}

[1] http://www.vogella.com/articles/GoogleAppEngineJava/ article.html

[2] Tamara Luarasi, Mimoza Durresi, Enhancing Distance Learning by Using the Android System and Cloud Computing 2012

[3] http://developer.android.com/guide/topics/media/audioc apture.html\#example

[4] http://www.deveature.com/2011/11/28/speechrecognizer-does-notwork-on-android-emulator/

[5] https://developers.google.com/appengine/docs/java/tools /eclipse

[6] http://www.cloud-interactive.com/web-app/

[7] http://www.j2eebrain.com/java-J2ee-advantages-ofservlets.html

[8] Michael Miller, Cloud Computing, Web-Based Applications that Change the Way You Work and Collaborate Online, 2008

[9] http://curiosity.discovery.com/question/targetedadvertising

[10] Shocking: Americans Spend More Time Socializing via Mobile than They Do Eating, http://blog.voxox.com/shocking-americans-spendmoretime-socializing-via-mobile-than-they-do-eating/4731

[11] http://www.forbes.com/sites/kimberlywhitler/2013/04/2 5/whyshould-marketers-care-about-mobile-marketing/

[12] Mobile Market Statistics 2013,http://www.smartinsights.com/mobilemarketing/m obile-marketing-analytics/mobile-marketing-statistics/

[13] gigaom.com/2012/08/13/marketing-is-dead-long-livemarketing/

[14] http://www.tsystemsus.com/umn/uti/508260_1/blobBina ry/White+Paper+Cloud+Computing $+\% 257 \overline{\mathrm{B}} \% 257 \mathrm{BPDF}$ $\% 252 \mathrm{C}+351+\mathrm{KB} \% 257 \mathrm{D} \% 257 \mathrm{D}$.pdf

[15] http://www.lexology.com/library/detail.aspx?g=3899e67 3-3797-46ad-a876-d1deb466e718

[16] http://www.advertisementjournal.com/2012/10/cloudcomputing/

[17] http://eandt.theiet.org/magazine/2012/05/cloudsbroadcastbenefits.cfm

[18] http://www.destinationcrm.com/Articles/ColumnsDepartments/Insight/Radian6-Sees-Cloud-ComputingAs-Future-of-Marketing-75295.aspx

[19] http://arxiv.org/ftp/arxiv/papers/0808/0808.3558.pdf

[20] http://www.verizonenterprise.com/resources/whitepaper s/itsolutions/wp_cloudcomputing_en Xg.pdf? ct return $=1$

[21] http://www.eecs.berkeley.edu/Pubs/TechRpts/2009/EEC S-2009-28.pdf

[22] http://www.cs.ucsb.edu/ lyouseff/CCOntology/CloudOn tology.pdf

[23] http://developer.android.com/about/index.html

[24] System and method for targeted marketing of goods and/or services to specific customers, US 7246083 B2

[25] http://www.tsystemsus.com/umn/uti/508260_1/blobBina ry/White+Paper+Cloud+Computing $+\% 257 \mathrm{~B} \% 257 \mathrm{BPDF}$ $\% 252 \mathrm{C}+351+\mathrm{KB} \% 257 \mathrm{D} \% 257 \mathrm{D}$.pdf

[26] Catherine Tyler Mooney, University of Oklahoma, Market Power, Audience Segmentation, and Radio Advertising Level
[27] Lars Vogel, Android BroadcastReceiver Tutorial 2013 http:/www.vogella.com/articles/AndroidBroadcastRecei ver/article.html

[28] Krasnoff, "Handling Phone Events in Android Programs" $\quad 19 \quad$ Sep $\quad 2012$ http://www.codeproject.com/Tips/462145/HandlingPhoneevents-in-Android-programs

[29] http://peacemoon.wordpress.com/2009/08/06/androidget-phonestate-when-someone-is-calling-usingbroadcastreceiver-example/

[30] http://developer.android.com/reference/android/telephon $\mathrm{y} /$ TelephonyManager.html 